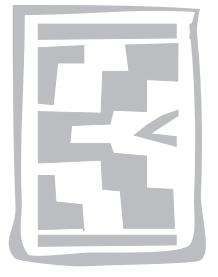

\title{
A preliminary investigation of tuberculosis and other diseases in African buffalo (Syncerus caffer) in Queen Elizabeth National Park, Uganda
}

\author{
G. KALEMA-ZIKUSOKA ${ }^{1}$, R.G. BENGIS ${ }^{2}$, A.L. MICHEL ${ }^{3}$ and M.H. WOODFORD ${ }^{4}$
}

\begin{abstract}
KALEMA-ZIKUSOKA, G., BENGIS, R.G., MICHEL, A.L. \& WOODFORD, M.H. 2005. A survey of tuberculosis and other diseases in African buffalo (Syncerus caffer) in Queen Elizabeth National Park, Uganda. Onderstepoort Journal of Veterinary Research, 72:145-151

A survey to determine the prevalence of bovine tuberculosis caused by Mycobacterium bovis and certain other infectious diseases was conducted on 42 free-ranging African buffaloes, (Syncerus caffer) from May to June 1997 in the Queen Elizabeth National Park, Uganda. Using the gamma interferon test, exposure to $M$. bovis was detected in $21.6 \%$ of the buffaloes. One dead buffalo and an emaciated warthog (Phacochoerus aethiopicus) that was euthanased, were necropsied; both had miliary granulomas from which $M$. bovis was isolated. None of the buffaloes sampled in Sector A of the park, which has no cattle interface, tested positive for bovine tuberculosis (BTB) exposure. The prevalence and distribution of BTB does not appear to have changed significantly since the 1960s, but this may be due to fluxes in the buffalo population. Serological testing for foot-and-mouth disease (FMD) demonstrated positive exposure of $57.1 \%$ of the buffaloes sampled, with types $A, O$ and SAT 1-3, which is the first known report of FMD antibodies to $A$ and $O$ types in free ranging African buffaloes. Foot-and-mouth disease virus types SAT 1 and SAT 3 were isolated from buffalo probang samples. Two percent of the buffaloes had been exposed to brucellosis. None of the buffaloes tested had antibodies to rinderpest, leptospirosis or $Q$ fever.
\end{abstract}

Keywords: African buffalo, bovine tuberculosis, foot-and-mouth disease, Syncerus caffer

\section{INTRODUCTION}

Bovine tuberculosis (BTB) caused by Mycobacterium bovis in African buffaloes (Syncerus caffer) in the Queen Elizabeth National Park (QENP) was first detected in the early 1960s (Thurlbeck, Butas, Mankiewicz \& Laws 1965). The first tuberculosis survey

1 Conservation Through Public Health, Plot 39, Babiiha Avenue, P.O. Box 10950, Kampala, Uganda

2 Directorate of Animal Health, P.O. Box 12, Skukuza, 1350 South Africa

3 Onderstepoort Veterinary Institute, Private Bag X05, Onderstepoort, 0110 South Africa

4 IUCN Veterinary Specialist Group

Accepted for publication 31 March 2005-Editor was performed in the QENP buffaloes in 1967. In this survey BTB was found in $38 \%$ of 64 buffaloes selected because of poor body condition and $10 \%$ of 52 buffaloes that were randomly selected (Woodford 1982a). In this study it was concluded that BTB in the buffaloes had originated from cattle, because this disease had been documented in cattle close to or bordering the park and infected buffaloes were only found in those sectors with a buffalo/cattle interface. The Maramagambo forest was thought to have been an adequate barrier to prevent the spread of BTB into sector A of the park, which is without a buffalo/cattle interface (Woodford 1982a). It was also concluded that BTB had spilled over from the buffaloes into warthogs since $9 \%$ of a sample of 90 warthogs in sectors $D$ and $E$ were found to be positive (Woodford 1982b). Bovine tuberculosis in the 
Kruger National Park (KNP) in South Africa is also believed to have originated from cattle (De Vos, Bengis, Kriek, Michel, Keet, Raath \& Huchzermeyer 2001; Bengis, Kock \& Fischer 2002) and the disease in buffaloes has subsequently been reported to have spilled over into lions, leopards, kudus, baboons and other species (Keet, Kriek, Penrith, Michel \& Huchzermeyer 1996; Bengis 1999; Keet, Kriek, Bengis, Grobler \& Michel 2000; Keet, Kriek, Bengis \& Michel 2001).

In the 1970 s and 1980 s, a $76.7 \%$ reduction of the QENP buffalo population occurred as a result of severe poaching during the civil wars (Eltringham \& Woodford 1973; Anon. 1996).

This study was initiated to determine whether the reduction in buffalo numbers in the 1970s and 1980s had any effect on the BTB prevalence reported in the earlier study, which took place in the late 1960s (Woodford 1982a). In the present study in the buffaloes, foot-and-mouth disease (FMD), rinderpest, brucellosis, leptospirosis and $Q$ fever, which are important infectious diseases of livestock, were also investigated.

\section{MATERIALS AND METHODS}

\section{Study site}

Queen Elizabeth National Park is a protected area bordering Lakes George and Edward and contains the Kazinga channel that connects the two lakes (Fig. 1). The park is unfenced and surrounding reserves have village enclaves in which there are cattle. The northern and southern parts are separated by the Maramagambo Forest of $320 \mathrm{~km}^{2}$, which appears to form a barrier for migration of buffaloes between the northern and southern sectors of the park (Woodford 1982a). The northern part is separated further into sectors $B, C, D, E$ and $F$ (Fig. 2). Sector $A$ is separated from sector $B$ by the incomplete barrier of the Maramagambo Forest, sector $B$ is separated from sector $C$ by the complete barrier of the Kazinga Channel, sector $C$ is separated from sector $D$ incompletely by the settlement at Katwe village and by the crater area.

\section{Immobilization techniques and sampling locations}

The buffaloes were darted from a four-wheel drive vehicle using a Daninject dart gun firing $1.5 \mathrm{~m} \ell$ Daninject darts. The anesthetic cocktail contained 7$8 \mathrm{mg}$ etorphine (Kyron, South Africa) plus $60-70 \mathrm{mg}$ xylazine (Kyron, South Africa). After sampling, the sedative effects of the cocktail on the buffaloes were reversed by the intravenous administration of 14$18 \mathrm{mg}$ diprenorphine (Kyron, South Africa) and 60$70 \mathrm{mg}$ yohimbine (Kyron, South Africa), respectively. Forty-two buffaloes were sampled from 18 different breeding herds and several bull groups.

Sampling was randomized in that the first animal in the herd that offered a clear shot was darted, two to three animals were sampled in each herd. There was some bias towards older animals since calves and yearlings were rarely sampled. Sampled buffalo herds were spatially distributed north and south of the Kazinga Channel in sectors $D$ and $B$, respectively, and also from sector A (Ishasha) south of the Maramagambo Forest.

\section{Samples}

Blood and oesophageal-pharyngeal probang samples were collected from 42 buffaloes. The blood was collected from the jugular vein or tail vein in heparinized and clot tubes. The probang samples were placed in sterile phosphate buffered saline (PBS) and stored in liquid nitrogen until further analysis at the Onderstepoort Veterinary Institute (OVI), South Africa. Blood in the heparinized tubes was divided into three $1.5 \mathrm{~m} \ell$ aliquots and each aliquot was incubated within $8 \mathrm{~h}$ of collection in three different reagents. The first aliquot was incubated in $30 \mu \ell$ of bovine tuberculin purified protein derivative (PPD) (ID-Lelystad, The Netherlands), the second aliquot in $60 \mu \ell$ of avian tuberculin PPD (ID-Lelystad, The Netherlands) and the third aliquot in a control of $30 \mu \ell$ of phosphate buffered saline (PBS) (Onderstepoort Veterinary Institute, South Africa) for 20$28 \mathrm{~h}$. After incubation, plasma was collected in cryovails and stored in liquid nitrogen until further analysis at the OVI tuberculosis laboratory in South Africa.

\section{Gamma interferon (IFN) assay for tuberculosis}

The commercially available Bovigam assay (CSL, Australia) was used according to the manufacturer's instructions for the execution of this test. A sandwich enzyme-linked immunosorbent assay (ELISA) was performed as described by Rothel, Jones, Corner, Cox \& Wood (1990). Unbound material was removed by washing after incubation. Horseradish peroxidase labeled anti-bovine IFN gamma was added. Unreacted conjugate was removed by washing after incubation. An enzyme substrate was added. The rate of conversion of this enzyme substrate was proportional to the amount of bound inter- 
feron (IFN)-gamma. The amount of colour development was estimated spectrophotometrically after termination of the reaction.

\section{Test for foot-and-mouth disease}

The oesophageal-pharyngeal probang sample from each buffalo was prepared for the isolation of FMD virus by grinding it in a mortar with a pestle and adding sufficient phosphate buffered saline to make a $10 \%$ tissue suspension. This was inoculated in $1 \mathrm{~m} \ell$ amounts into ten tubes containing cultures of primary porcine kidney cells, which were then incubated at $37^{\circ} \mathrm{C}$ for $48 \mathrm{~h}$. Cultures were observed daily for cytopathic effects. Cultures not showing cytopathic effects after $48 \mathrm{~h}$ were incubated for a further $48 \mathrm{~h}$. Supernatants from affected cultures were used to type the viral isolate by antigen capture ELISA using the method described by Roeder \& Le Blanc Smith (1987).

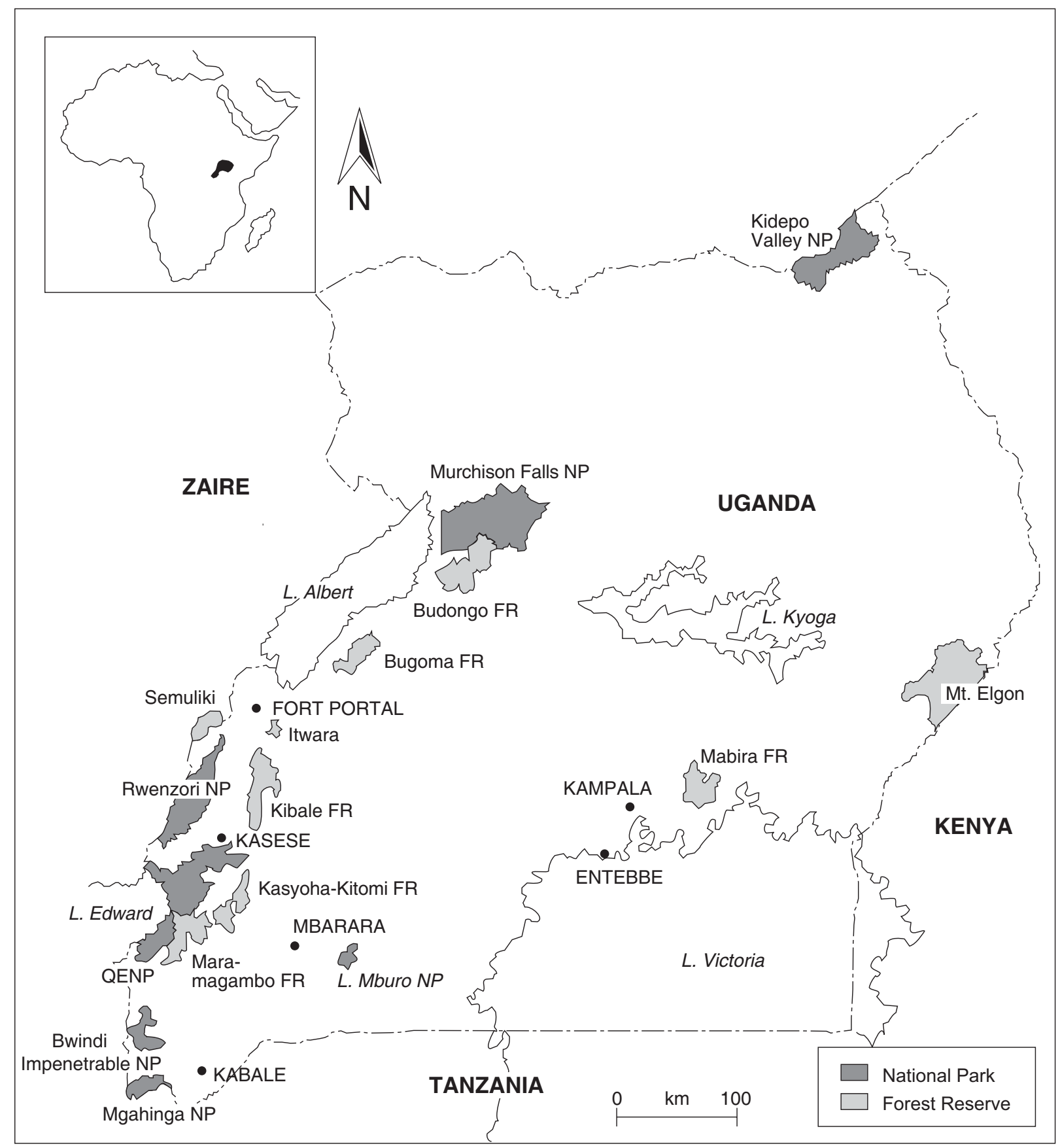

FIG. 1 Location plan 


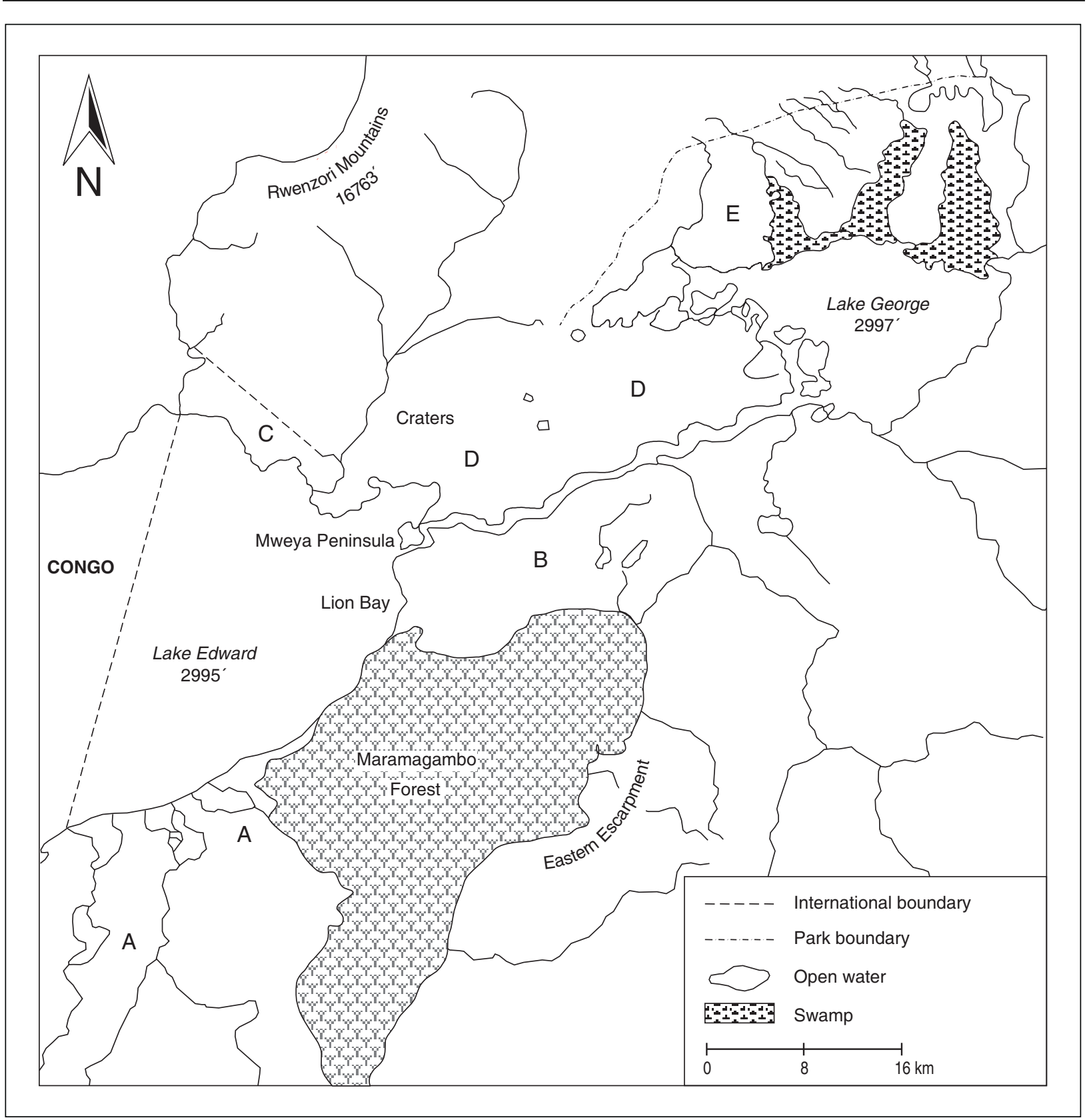

FIG. 2 Queen Elizabeth National Park, study sectors

\section{Serology}

A competitive antibody ELISA test and a liquid phase blocking ELISA test were used to test for exposure to rinderpest (Anderson, Barrett \& Scott 1997) and FMD (Hamblin, Barnett \& Hedger 1986), respectively. An indirect immunofluoresence assay (IFA) (To, Htwe, Kako, Kim, Yamaguchi, Fukushi \& Hirai 1998) was used to detect antibodies to Coxiella burnetii ( $Q$ fever).

Serum agglutination (Adesiyun \& Cazabon 1996) and complement fixation tests (Jones, Hendricks \&
Berman 1963) were used to detect antibodies to Brucella abortus. Microscopic agglutination tests (MAT) and serum neutralization tests as described by Leighton \& Kuiken (2001) were used to determine exposure to Leptospira serotypes.

\section{Postmortem examinations}

Permission was also obtained to euthanase three emaciated animals for study. A female warthog, one buffalo cow and one male baboon were euthanased using suxamethonium chloride (Scoline, Kyron, 
South Africa). A dead buffalo cow found intact, which was estimated to have been dead for less than $12 \mathrm{~h}$, was also necropsied. Samples of lesions in these animals were collected and frozen for mycobacterial culture as described previously (Bengis, Kriek, Keet, Raath, De Vos \& Huchzermeyer 1996) and additional samples were placed in $10 \%$ formaldehyde for histopathological examination at the OVI.

\section{RESULTS}

All the darted buffaloes were in good bodily condition with no overt clinical signs of BTB. No ungulates with overt clinical signs suggestive of rinderpest were observed in the park during this study. Buffalo sampling was restricted to sectors $A, B$ and $D$ because buffalo herds living in the vicinity of human communities in sectors $C$ and $E$ were difficult to approach within darting range as a result of poaching, which occurs on a significant scale.

Eight $(21.6 \%)$ out of 38 buffaloes were positive reactors to $M$. bovis on the gamma IFN test, which took into consideration $M$. avium and the positive control. Four of the samples were not interpretable. The dead buffalo and the warthog that was euthanased had diffuse miliary granulomas present in many lymph nodes, liver and lungs from which $M$. bovis was isolated. The emaciated buffalo was not suffering from tuberculosis and the loss of bodily condition was attributable to severe dental attrition. The emaciated baboon that was euthanased and necropsied had granulomatous lung lesions, but $M$. bovis was not isolated from them. Histopathologically, the lung lesions were shown to be caused by a trematode, probably a Paragonimus sp. (Georgi 1985).

The prevalence of FMD antibody was $57.14 \%$. Positive animals had antibodies to one or more of the viral types. Of these positive buffaloes, $83.3 \%$ had antibodies to SAT $1,29.2 \%$ to SAT $2,33.3 \%$ to SAT 3, $20.8 \%$ to type A and $58.3 \%$ to type O. A SAT 1 type virus was isolated from two probang samples, and SAT 3 type virus from another. One of the 42 buffaloes reacted positive in the serum agglutination and complement fixation tests for $B$. abortus. A second buffalo was a weak positive reactor in these two tests and was considered suspect. The remaining 40 animals tested negative for brucellosis.

All the buffaloes tested were serologically negative for rinderpest, $Q$ fever and Leptospira serotypes.

\section{DISCUSSION}

When comparing the results of the current BTB survey with the survey conducted in the 1960s, it is important to note that the results of the earlier survey were based on lesions found at post-mortem examinations and histopathology with culture of a certain percentage of samples (Woodford 1982a). Mycobacterium bovis was responsible for 12 out of 14 infections typed from buffaloes and for two out of six typed from warthogs. Atypical mycobacteria were responsible for the balance of infections typed and was thought to be from fish, frogs or birds (Woodford 1982a, 1982b). Therefore, the 1960 study results are rough approximations of the actual BTB prevalence. Recent studies, however, have found an excellent correlation between necropsy and culture findings of culled buffaloes and the blood-based gamma IFN test used in this survey (Grobler, Michel, De Klerk \& Bengis 2002). In both buffalo surveys conducted in the 1960s and this current one mainly mature buffaloes were sampled to increase the likelihood of detecting infected animals (Bengis 1999, De Vos et al. 2001).

The current survey demonstrated that the BTB prevalence in QENP buffaloes has not changed significantly over 30 years, and that spillover infection from buffaloes into warthogs is still occurring. However, this study did not investigate the possibility of warthogs being maintenance hosts of BTB. One of the reasons why the TB prevalence may not have changed significantly over 30 years is that extensive poaching of buffaloes and other large mammals, including elephants, occurred during the period of Ugandan civil wars in the 1970s and 1980s. The buffalo numbers decreased by $76.7 \%$, i.e. from 18000 to 4200 (Eltringham \& Woodford 1973, Anonymous 1996). If it is assumed that BTB transmission is density dependent, then this population decrease may have reduced the rate of spatial spread of the disease within and between the buffalo herds. The population has now grown to over 10000 animals (Richard Lamprey, personal communication 2002) and, although the prevalence appears to have remained the same, it may have been tracking the population densities, and is now increasing progressively, as has been reported from the KNP (De Vos et al. 2001).

The African buffalo, being a wild bovid with similar habits to cattle, as well as filling a similar ecological niche, may be a good indicator species for monitoring certain cattle associated diseases such as BTB and rinderpest. Cattle, in turn, may be considered sentinels for detecting certain Afro-endemic dis- 
eases in buffaloes. Cattle still graze illegally in the park and use water holes in the interior and the periphery of QENP, creating a diffuse interface for them to mix with buffaloes, with the potential of bidirectional transmission of infectious diseases. Bovine tuberculosis is a chronic erosive disease, but because it does not have a high clinical profile in cattle, it is not considered to be as important in Uganda as the epidemic viral diseases of ruminant cattle such as FMD and rinderpest which may cause severe morbidity and mortality in cattle (Bengis et al. 2002).

In Africa, buffaloes are known maintenance hosts of FMD viral types SAT 1, SAT 2 and SAT 3 (Hedger 1972; Sutmoller, Thomson, Hargreaves, Foggin \& Anderson 2000). The results of this survey show that the QENP buffaloes are no exception regarding these types. However, the finding of antibodies to types $A$ and $O$ was surprising, as this has not been previously recorded in free-ranging African buffalo populations (Thomson, Vosloo \& Bastos 2003). The buffalo pharyngeo-oesophageal probang samples, however, only yielded SAT 1 and SAT 3 types. There remains a possibility that some of the QENP buffaloes sampled had cross-reactions to the FMD $A$ and $O$ types (Vosloo, personal communication 2003). Genome sequencing studies on these buffalo isolates demonstrated that the Uganda SAT 1 buffalo strain from this survey was distinct from SAT 1 strains of buffaloes in Zambia, Malawi, Namibia, Zimbabwe, Botswana, Swaziland, KNP and other parts of South Africa (Thomson et al. 2003).

Cattle in the village enclaves around QENP suffer from sporadic FMD outbreaks, almost on a yearly basis (Joram Tumushabe, personal communication 2002), causing morbidity, and in some instances, mortality. Molecular epidemiological studies to characterize the strains infecting the cattle and to compare them with buffalo strains would help to identify FMD vaccine candidates, which could be used to protect these cattle. Cattle and buffalo isolates may possibly even one day yield one of the Afro-alien types (A, O, C and Asia 1).

The low prevalence of brucellosis reactors in the QENP buffaloes could indicate that they are not maintaining the disease, or possibly have limited exposure from a low prevalence cattle source. However, it has been reported that if brucellosis cannot be maintained in bovidae populations, another Brucella species other than Brucella abortus may be involved, emphasizing the importance of brucellosis bacteriology and ruling out contact with other Brucella spp. infected domestic livestock. The preva- lence of brucellosis in the cattle at the interface needs to be examined further, because, as with BTB, brucellosis is also of public health significance and humans can get infected through consumption of raw milk. The low prevalence of brucellosis reactors could also be attributed to the lack of sensitivity of the serum agglutination and complement fixation tests (CFT) employed in the survey. When the tests were performed in 1997, the CFT was the most sensitive test and recommended as the confirmatory test for brucellosis. However, a more recent indirect ELISA test appears to be more sensitive than the CFT (Paweska et al. 2002) and would be good to use for future surveys.

The absence of antibodies to rinderpest in the QENP buffaloes sampled is in agreement with previous findings. Rinderpest has not been reported from this part of Uganda since the 1930s (Plowright, Laws \& Rampton 1964). There are also no published reports to date of outbreaks of leptospirosis or $Q$ fever in livestock or humans, even though the causative organisms are rather ubiquitous in nature.

Unfortunately, buffaloes at the periphery of the park that were more likely to mix with cattle could not be sampled in this survey. This area has been subject to severe poaching and the buffaloes were consequently nervous and difficult to approach with a vehicle. Follow-up studies are necessary to investigate the prevalence of significant ruminant diseases at this buffalo/livestock interface, and to compare results with cattle that live further away from the park in order to determine the direction of disease transmission between these two closely related species. Education of cattle keepers and park staff on the risks of disease transmission between buffaloes and livestock could potentially reduce the historical resentment of cattle keepers to not being allowed to legally graze their animals in this park since it was gazetted in 1952.

\section{ACKNOWLEDGEMENTS}

We thank the Uganda Wildlife Authority and the South African National Directorate of Animal Health for permission and logistical assistance to carry out this study, the Food and Agricultural Organization, Care For The Wild, Makerere University Faculty of Veterinary Medicine (MUK/FVM) and Uganda Government Veterinary Services for funds and logistical assistance, Dr Eric Edroma (UWA executive director), Dr Ludwig Siefert (senior lecturer from MUK/ FVM), Abdullah Latiff (chief park warden of QENP), Marcello Onen, Tom Friday and Joseph Machati 
(field assistants and ranger from QENP) for logistical and technical assistance, and Dr Suzanne Kennedy-Stoskopf from North Carolina State University for editorial assistance and comments on the manuscript.

\section{REFERENCES}

ADESIYUN, A.A. \& CAZABON, E.P. 1996. Seroprevalences of brucellosis, $Q$ fever and toxoplasmosis in slaughter livestock in Trinidad. Revue d'élevage et de médecine vétérinaire des pays tropicaux, 49:28-30.

ANDERSON, J., BARRETT, T. \& SCOTT, G.R. 1997. Manual on the diagnosis of rinderpest, $3^{\text {rd }}$ ed. Rome: FAO.

ANONYMOUS 1996. A survey of the wildlife protected areas of Uganda, Phase I: September 1995 - January 1996. Report to the Uganda Government by the Ministry of Tourism, Wildlife and Antiquities.

BENGIS, R.G., KRIEK, N.P.J., KEET, D.F., RAATH, J.P., DE VOS, V. \& HUCHZERMEYER, H. 1996. An outbreak of bovine tuberculosis in a free-living African buffalo (Syncerus caffer-Sparrman) population in the Kruger National Park: a preliminary report. Onderstepoort Journal of Veterinary Research, 63:15-18.

BENGIS, R.G. 1999. Tuberculosis in free-ranging mammals, in Zoo and Wild Animal Medicine, Current Therapy 4, edited by M.E. Fowler. Philadelphia, Pennsylvania: W. B. Saunders Company

BENGIS, R.G., KOCK, R.A. \& FISCHER, J. 2002. Infectious animal diseases: the wildlife/livestock interface. Revue Scientific et Technique, 21:53-65.

DE VOS, V., BENGIS, R.G., KRIEK, N.P.J., MICHEL, A., KEET, D.F., RAATH, J.P. \& HUCHZERMEYER, H.F. 2001. The epidemiology of tuberculosis in free-ranging African buffalo (Syncerus caffer) in the Kruger National Park, South Africa. Onderstepoort Journal of Veterinary Research, 68:119-130.

ELTRINGHAM, S. \& WOODFORD, M.H. 1973. The numbers and distribution of buffalo in the Rwenzori National Park, Uganda. East African Wildlife Journal, 11:151-164.

GEORGI, J.R. 1985. Parasitology for Veterinarians. Philadelphia, Pennsylvania: W. B. Saunders Company.

GROBLER, D.G., MICHEL, A.L., DE KLERK, L. \& BENGIS, R.G. 2002. The gamma interferon test: its usefulness in a bovine tuberculosis survey in African buffaloes (Syncerus caffer) in the Kruger National Park. Onderstepoort Journal of Veterinary Research, 69:221-227.

HAMBLIN, C., BARNETT, I.T.R. \& HEDGER, R.S. 1986. A new enzyme-linked immunosorbent assay (ELISA) for the detection of antibodies against foot-and-mouth disease virus. Journal of Immunological Methods, 93:115-121.

HEDGER, R.S. 1972. Foot-and-mouth disease and the African buffalo (Syncerus caffer). Journal of Comparative Pathology, 82:19-28.

JONES, L.M., HENDRICKS, J.R. \& BERMAN, D.T. 1963. The standardization and use of the complement-fixation test for the diagnosis of bovine brucellosis with a review of the literature. American Journal of Veterinary Research, 24:11431151.

KEET, D.F., KRIEK, N.P.J., PENRITH, M.L., MICHEL, A. \& HUCHZERMEYER, H. 1996. Tuberculosis in buffaloes (Syncerus caffer) in the Kruger National Park: Spread of the disease to other species. Onderstepoort Journal of Veterinary Research, 63:239-244.

KEET, D.F., KRIEK, N.P.J., BENGIS, R.G., GROBLER, D.G. \& MICHEL, A. 2000. The rise and fall of tuberculosis in a freeranging chacma baboon troop in the Kruger National Park. Onderstepoort Journal of Veterinary Research, 67:115-122.

KEET, D.F., KRIEK, N.P.J., BENGIS, R.G. \& MICHEL, A.L. 2001. Tuberculosis in kudus (Tragelaphus strepsiceros) in the Kruger National Park. Onderstepoort Journal of Veterinary Research, 68:225-230.

LEIGHTON, F.A. \& KUIKEN, T. 2001. Bacterial infections, leptospirosis, in Infectious diseases of wild mammals, $3^{\text {rd }}$ ed., edited by E.S. Williams \& I.K. Barker. Ames, lowa: lowa State University Press.

PLOWRIGHT, W., LAWS, R.M. \& RAMPTON, C.S. 1964. Serological evidence for the susceptibility of the hippopotamus (Hippopotamus amphibius Linnaeus) to natural infection with rinderpest virus. Journal of Hygiene (London), 62: 329-336.

ROEDER, P.L. \& LE BLANC SMITH, P.M. 1987. Detection and typing of foot-and-mouth disease virus by enzyme-linked immunosorbent assay, a sensitive, rapid and reliable technique for primary diagnosis. Research in Veterinary Science, 43:225-232.

ROTHEL, J.S., JONES, S.L., CORNER, L.A., COX, J.C. \& WOOD, P.R. 1990. A sandwich enzyme immunoassay for bovine interferon gamma and its use for the detection of tuberculosis in cattle. Australian Veterinary Journal, 67:134137.

SUTMOLLER, P., THOMSON, G.R., HARGREAVES, S.K., FOGGIN, C.M. \& ANDERSON, E.C. 2000. The foot-andmouth disease risk posed by African buffalo within wildlife conservancies to the cattle industry of Zimbabwe. Preventive Veterinary Medicine, 44:43-60.

TO, H., HTWE, K.K., KAKO, N., KIM, H.J., YAMAGUCHI, T., FUKUSHI, H. \& HIRAI, K. 1998. Prevalence of Coxiella burnetti in dairy cattle with reproductive disorders. Journal of Veterinary Medical Science, 60:859-861.

THOMSON, G.R., VOSLOO, W. \& BASTOS, A.D.S. 2003. Footand-mouth disease in wildlife. Virus Research, 91:145-161.

THURLBECK, W.M., BUTAS, C.A., MANKIEWICZ, E.M. \& LAWS, R.M. 1965. Chronic pulmonary disease in wild buffalo (Syncerus caffer) in Uganda. American Review of Respiratory Diseases, 92:801-805.

WOODFORD, M.H. 1982a. Tuberculosis in wildlife in the Ruwenzori National Park, Uganda (Part I). Tropical Animal Health and Production, 14:81-88.

WOODFORD, M.H. 1982b. Tuberculosis in wildlife in the Ruwenzori National Park, Uganda (Part II). Tropical Animal Health and Production, 14:155-160. 